\title{
COMPTON SCATTERING TOMOGRAPHY FOR AGRICULTURAL MEASUREMENTS
}

\author{
PAULO E. CRUVINEL ${ }^{1}$, FATAi A. BALOGUN ${ }^{2}$
}

\begin{abstract}
This paper presents a new approach in tomographic instrumentation for agriculture based on Compton scattering, which allows for the simultaneous measurements of density and moisture of soil samples. Compton tomography is a technique that can be used to obtain a spatial map of electronic density of samples. Quantitative results can be obtained by using a reconstruction algorithm that takes into account the absorption of incident and scattered radiation. Results show a coefficient of linear correlation better than 0.81 , when comparison is made between soil density measurements based on this method and direct transmission tomography. For soil water contents, a coefficient of linear correlation better than 0.79 was found when compared with measurements obtained by time domain reflectrometry (TDR). In addition, a set of Compton scatter images are presented to illustrate the efficacy of this imaging technique, which makes possible improved spatial variability analysis of pre-established planes.
\end{abstract}

KEYWORDS: Compton tomography, soil density and moisture, agricultural automation.

\section{TOMÓGRAFO DE ESPALHAMENTO COMPTON PARA MEDIDAS AGRÍCOLAS}

RESUMO: Este trabalho apresenta uma nova instrumentação tomográfica para agricultura baseada em espalhamento Compton, a qual viabiliza a medida simultânea da densidade e da umidade de amostras de solo. A tomografia Compton é uma técnica que possibilita o mapeamento espacial das densidades eletrônicas de uma amostra. Resultados mostram coeficiente de correlação linear melhor que 0,81 para medidas comparativas realizadas entre esse método e a técnica de tomografia por transmissão. Para a medida de umidade do solo, um coeficiente de correlação linear melhor que 0,79 foi encontrado, quando da comparação com a técnica de reflectrometria no domínio do tempo (RDT). Adicionalmente, um conjunto de imagens obtidas tomograficamente por espalhamento Compton é apresentado para ilustrar a eficácia da técnica desenvolvida, a qual viabiliza analisar a variabilidade espacial em planos pré-selecionados.

PALAVRAS-CHAVE: tomografia Compton, densidade e umidade de solo, automação agrícola.

\section{INTRODUCTION}

Nondestructive-testing practitioners challenged by complex products can choose sophisticated methods and systems, such as computerized tomography, emission tomography or one of several magnetic resonance imaging systems developed for other applications. Computerized tomography (CT) a technique pioneered by Cormack and Hounsfield permits imaging of objects in axial cross sections (CORMACK, 1973; HOUNSFIELD, 1973). These images can then be stored as a stack of two-dimensional (2D) matrices of numbers. Despite the proven success of these techniques in diverse fields, studies of applications of scattered photons have continued to gain momentum within the past decade. Both coherently and incoherently scattered photons and a technique employing the energy

\footnotetext{
${ }^{1}$ Doctor in Automation, Researcher at the Embrapa Agricultural Instrumentation, e-mail: cruvinel@ cnpdia.embrapa.br

${ }^{2}$ Physics Professor, Researcher at the Physics Department, Obafemi Awolowo University, Ile-Ife, Nigeria.

Recebido pelo Conselho Editorial em: 2-9-2004

Aprovado pelo Conselho Editorial em: 31-3-2006 
profile of Compton scatter peaks have been used variously and in combination to characterize body tissues such as bones, soft tissue, lungs and fats. Compton scattering measurements have found applications such as quality control in manufacturing machine tools, and automotive parts, as well as for monitoring high temperature environments of molten metals. In all these cases, the compactness of the required instrumentation allows placement of both source and detector on the same side of the object whose density is to be measured. Use of back-scattering angles has been shown to improve the sensitivity and enhance the reproducibility of measurement (GIGANTE \& HANSON, 1989).

Apart from single-point densitometry, density mapping of a plane of interest (imaging) has been performed on various objects. The advantages often cited include, for various reasons, partial body imaging, accessibility, and reduced need for computational image reconstruction. However, applicability of this technique had been limited due to a number of factors. These include systematic uncertainties as to attenuation of both incident and scattered beam of photons in the object, contribution of multiple scattered photons to the useful signal, and scattering volume from which the useful signal is derived. In 1993, Balogun and collaborators have studied the variation of scattering volume with scattering angle using a numerical-analysis-based computer algorithm (BALOGUN \& SPYROU, 1993). The thickness dependence of scattered photon fluency was demonstrated for an epoxy-resin sample examined at a $150^{\circ}$ scattering angle using the $60 \mathrm{keV}$ photon energy of ${ }^{241} \mathrm{Am}$. A value of $5 \mathrm{~cm}$ was obtained for the saturation thickness.

X-ray computerized tomography (CT) one of several types of direct transmission tomographic systems applied by Embrapa Agricultural Instrumentation Center since 1984, is now recognized as a versatile technique by both soil science and various industrial sectors (PETROVIC et al., 1982; HAINSWORTH \& AYLMORES, 1983; CRESTANA et al. 1985; CRUVINEL et al., 1987, 1990). In the present study, designed to overcome problems incurred by direct transmission tomography methods, we report results of a dedicated Compton scattering tomography scanners, developed for agricultural applications.

\section{THEORETICAL BACKGROUND}

An incident gamma or an X-ray can interact with matter including soils of several forms. The probable interaction forms can happen mutually or generally in form of coherent scattering, incoherent scattering, photoelectric effect, and pair production. In photoelectric interaction, the energy of the incoming photon is completely absorbed by an orbital electron, while a partial energy loss is suffered by the photon as it undergoes an incoherent scattering with a virtually free electron (BEISER, 1969). In the last case, the target electron and the scattered photon share the photon's energy. In the case of pair production, an incident photon, in the presence of a nuclear field, is converted to an electron positron pair. Interactions via coherent scattering route entail no loss of energy by the incident photon. Several forms of radiation interaction with matter are dependent of the incident photon energy, but they're also influenced and modulated according to the $\mathrm{Z}$ atomic number of the target elements.

If the partial interaction probabilities of the various modes of interaction modes are plotted against photon energies, the range of influence of each mode is clearly apparent. This shows that below $30 \mathrm{keV}$ of photon energy, photoelectric effect is dominant with coherent scattering showing some contribution. Above this level and up to $60 \mathrm{keV}$ is a mixture of photoelectric effect and, coherent and incoherent scattering. In the range $60 \mathrm{keV}$ to a few $\mathrm{MeV}$ range, however, incoherent scattering takes over as the dominant mode of gamma interaction in soil. Pair production begins from $1.22 \mathrm{MeV}$ becoming relevant only at high energy at several $\mathrm{MeV}$ of photon energy.

Thus, among this limits of $60 \mathrm{keV}$ and $1.33 \mathrm{MeV}$, from commercially available radioisotopes, the predominant interaction mode of gamma rays in soil is the incoherent or Compton scattering. As 
scattering predominates, the Klein-Nishina differential cross section for a free electron is given uniquely by the energy and angle relationship, such us:

$$
\frac{\mathrm{d}_{\mathrm{e}} \sigma^{\mathrm{KN}}(\mathrm{E})}{\mathrm{d} \Omega}=\frac{\mathrm{r}_{0}^{2}}{2}\left[\frac{1+\cos ^{2} \theta}{\left(1+\alpha\left(1-\cos \theta \mathrm{os}^{2}\right.\right.}\left[1+\frac{\alpha^{2}\left(1-\cos \theta \mathrm{o}^{2}\right.}{\left(1+\cos ^{2} \theta\right)(1+\alpha(1-\cos \theta \mathrm{os}}\right]\right]
$$

where,

$\mathrm{r}_{0}$ - classical electron radius numerically equal to $2.818 \times 10^{-15} \mathrm{~m}$;

$\theta$ - scattering angle of the scattered photon, and

$\alpha$ - rate between the energy $E$ of the incident photon and the rest mass energy of the electron, which is equal to $511 \mathrm{keV}$.

The validity of equation (1) occurs when the photon energy is much larger than the binding energy of the target electrons. Hence one can say that the number of scattered photons is expected to be proportional for such energy to the bulk density or water content respectively. In a more realistic form, the beams of incident and scattered photons suffer attenuation in traveling from the source through the sample to the scattering volume and, hence to the detector. In order to consider this, we can write the equation (2), for the number of single scattered photons detected at the detector as:

$$
\left.\mathrm{S}(\mathrm{E})=\mathrm{I}_{0}(\mathrm{E}) \mathrm{t} \varepsilon \mathrm{E}\right) \mathrm{t}\left(-\int_{\mathrm{x} 1} \mu_{1}(\mathrm{x}, \mathrm{E}) \mathrm{dx}\right) \frac{\mathrm{d}_{\mathrm{e}} \sigma^{\mathrm{KN}}(\mathrm{E})}{\mathrm{d} \Omega} \rho \frac{\mathrm{N}_{\mathrm{A}} \mathrm{Z}}{\mathrm{A}} \exp \left(-\int_{\mathrm{x} 2} \mu_{2}(\mathrm{x}, \mathrm{E}) \mathrm{dx}\right) \mathrm{dVd} \Omega
$$
where,

$\mathrm{t}$ - time in seconds during a counting period;

$\mathrm{I}_{0}(\mathrm{E})$ - incident photon flux with energy $\mathrm{E}$;

$\frac{\mathrm{d}_{\mathrm{e}} \sigma^{\mathrm{KN}}(\mathrm{E})}{\mathrm{d} \Omega}$ - Klein-Nishina differential cross-section at energy $E$ for a free electron;

$\mathrm{d} \Omega$ - differential angle related to the Klein-Nishina differential cross-section;

$\rho$ - bulk density;

$\mathrm{Z}$ - atomic number;

$\mathrm{N}_{\mathrm{A}}$ - Avogadro's number;

$\mathrm{N}$ - mass number of the material under investigation.

$\mu_{1}$ and $\mu_{2}$ - linear attenuation factors of the attenuation of the primary and scattered photons within the sample;

$\varepsilon$ - detector's photopeak counting efficiency at the scattered photon energy;

$\mathrm{x}_{1}$ and $\mathrm{x}_{2}$ - length of the paths of the photons in the sample from the source to the scattering center and back to the detector respectively, and

$\mathrm{dV}$ - differential volume considered for the radiation and its interaction with the matter.

\section{MATERIAL AND METHODS}

The soil used in this study was collected in the experimental field of Pindorama, SP, Brazil, part of the Agronomic Institute of Campinas, inside a $5000 \mathrm{~m}^{2}$ area of combined Brazilian Podzol (Paleuhumult) and red-yellow Brazilian Latosol from Motuca - SP, Brazil. To calibrate soil bulk density measurements, a set of air-dried and sieved soil samples were placed in a number of $50 \times 50 \mathrm{x}$ $80 \mathrm{~mm}$ Plexiglass boxes.

To calibrate soil water content measurements, a set of sieved soil samples with different moisture content was also put into various 50 × 50 × $80 \mathrm{~mm}$ Plexiglass boxes.

The experimental set-up consisted of two radioactive sources, one of ${ }^{137} \mathrm{Cs}$ for soil bulk density measurements and the other of ${ }^{231} \mathrm{Am}$ for water content measurements, emitting gamma ray energies of 
$662 \mathrm{keV}$ and $60 \mathrm{keV}$ respectively. The counting geometry employed was designed to increase available incident flux and reduce experimental time required for a given counting precision. Activity of the radioactive sources during the experiment was $600 \mathrm{mCi}$ and $300 \mathrm{mCi}$.

The counting time employed for each energy was 50 seconds per sampled point on the projection with a spatial resolution of $2 \mathrm{~mm}$, a total of 30 sampled points per projection and a total $10 \mathrm{~cm}$ vertical displacement.

Figure 1 in the block diagram shows the architecture of the Compton scattering tomography scanning system, which consists of two radioactive sources (one operating with $60 \mathrm{keV}$ and the second one with $662 \mathrm{keV})$, and scintillator detector $(\mathrm{NaI}(\mathrm{Tl}))$ assembled over a mechanical ring device; two stepper motors were presented: one for translation and one for vertical shift of the sample.

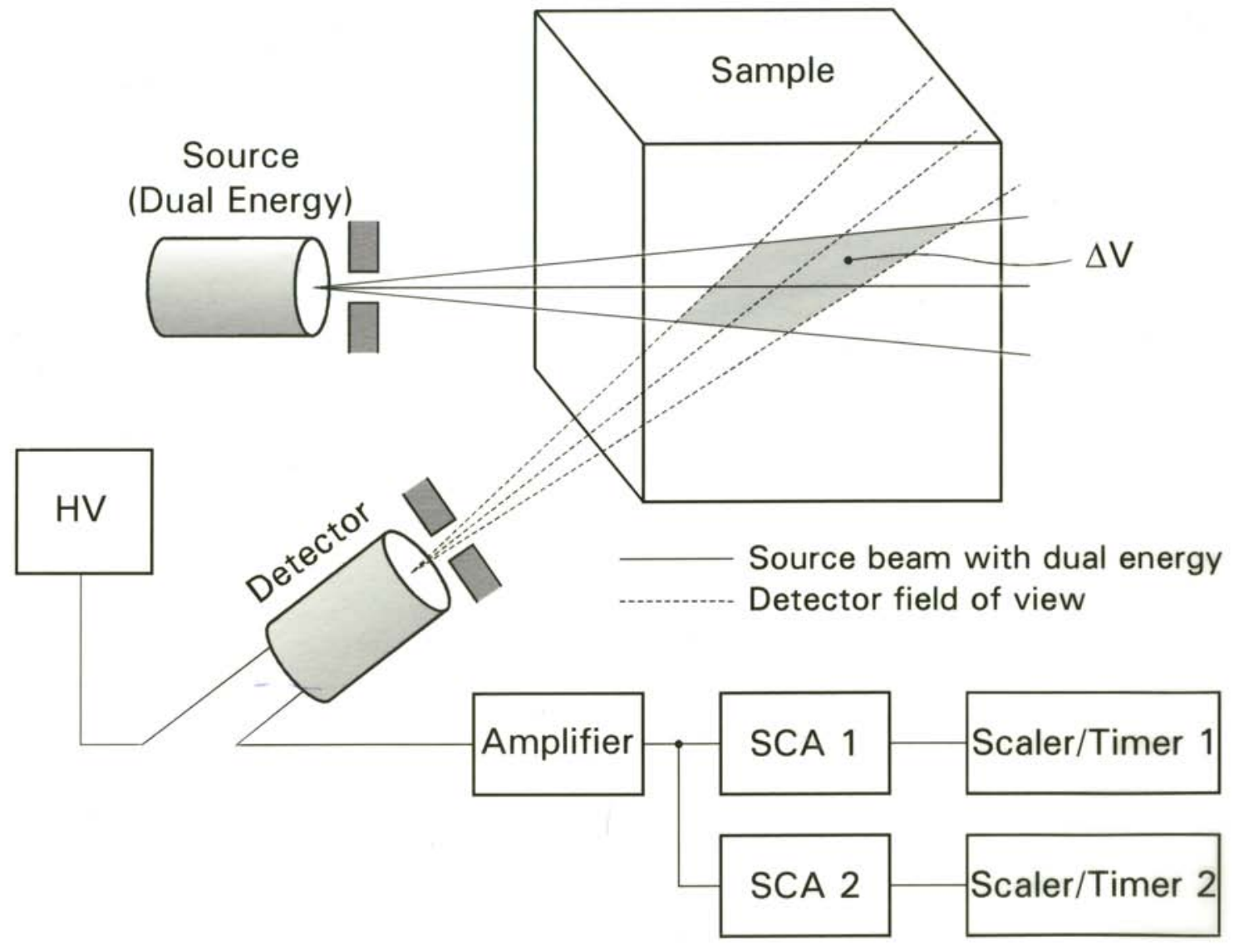

FIGURE 1. Block diagram for the Agricultural Compton scattering tomography. It is used two radioactive source i.e., one operating at $60 \mathrm{keV}$ and the second one at $662 \mathrm{keV}$. A high voltage power supply (HV) operating at 960 Volts feeds a scintillator detector ( $\mathrm{NaI}(\mathrm{Tl})$ ). The output signal of the detector is amplified and discriminated by means of two single channel analyzer (SCAs), each one enabled to operate in the region of a given energy, as well as to allow the counters to count the scattered photons under a specific time.

The manner to facilitate the implementation of the platform and become more modular was to develop five nuclei that permitted the end user of the system complete use of the form of architecture that was the most intuitive and thus became transparent to the end user of the processor architecture. 
Of these modules, three were developed in $\mathrm{C}$ and were executed in the architecture. These three modules for three-dimensional and two-dimensional parallel reconstruction algorithms were implemented respectively by means of the adaptive filter and 2D wavelets. Additionally, the Hamming, wavelets $1 \mathrm{D}$, and the signal restoration were implemented in the module of twodimensional reconstruction. The other two modules were developed in the Windows environment with the use of Borland Builder C++ version 5.0. These modules are responsible for interfacing with the reconstruction modules, becoming a totally independent interface as the reconstructions occur. The graphic interface permits the selection of the data files having projections that will be reconstructed through the three-dimensional and two-dimensional parallel algorithms. With these applications, one can make a two-dimensional visualization permitting the selection of the region of interest, using the gray-level (or pseudo-colors) tones to represent the density or moisture encountered in an analyzed sample. Besides this, one can also choose the parameters of filtration and regions of interest.

\section{RESULTS AND DISCUSSION}

Figure 2 shows of the Compton tomography instrument for agricultural application, which is based on the application of two single channel analyzers and two digital counters and timers.

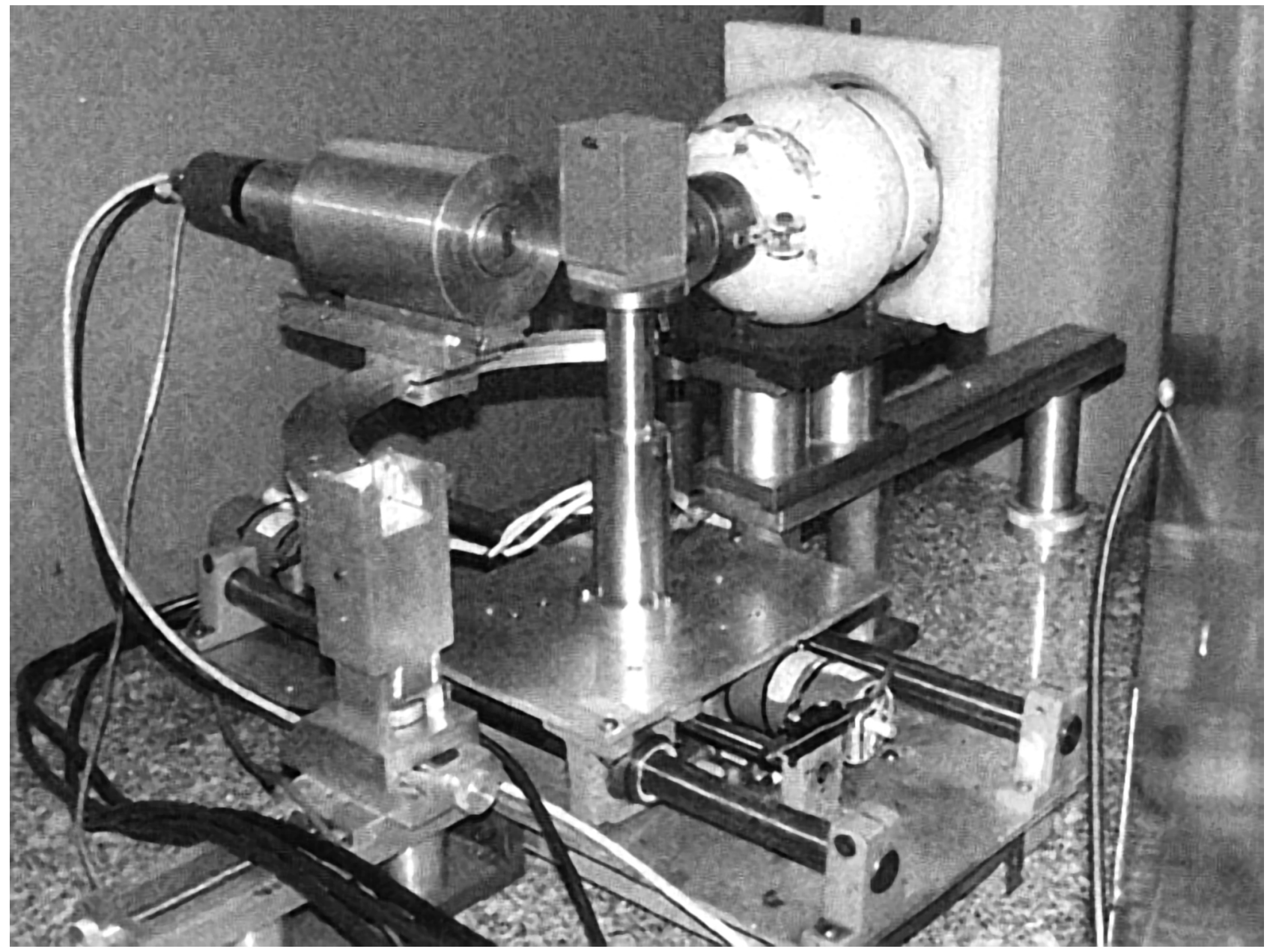

FIGURE 2. Compton scattering tomography scanning system (Dual energy source operating with $60 \mathrm{keV}$ and $662 \mathrm{keV}$, the scintillator detector assembled over a mechanical ring device; two stepper motors, one for translation and one for vertical shift of the sample). 
Figure 3 shows the angular dependence of the scattering volume of the sample and the number of counts, as described by equation (1).

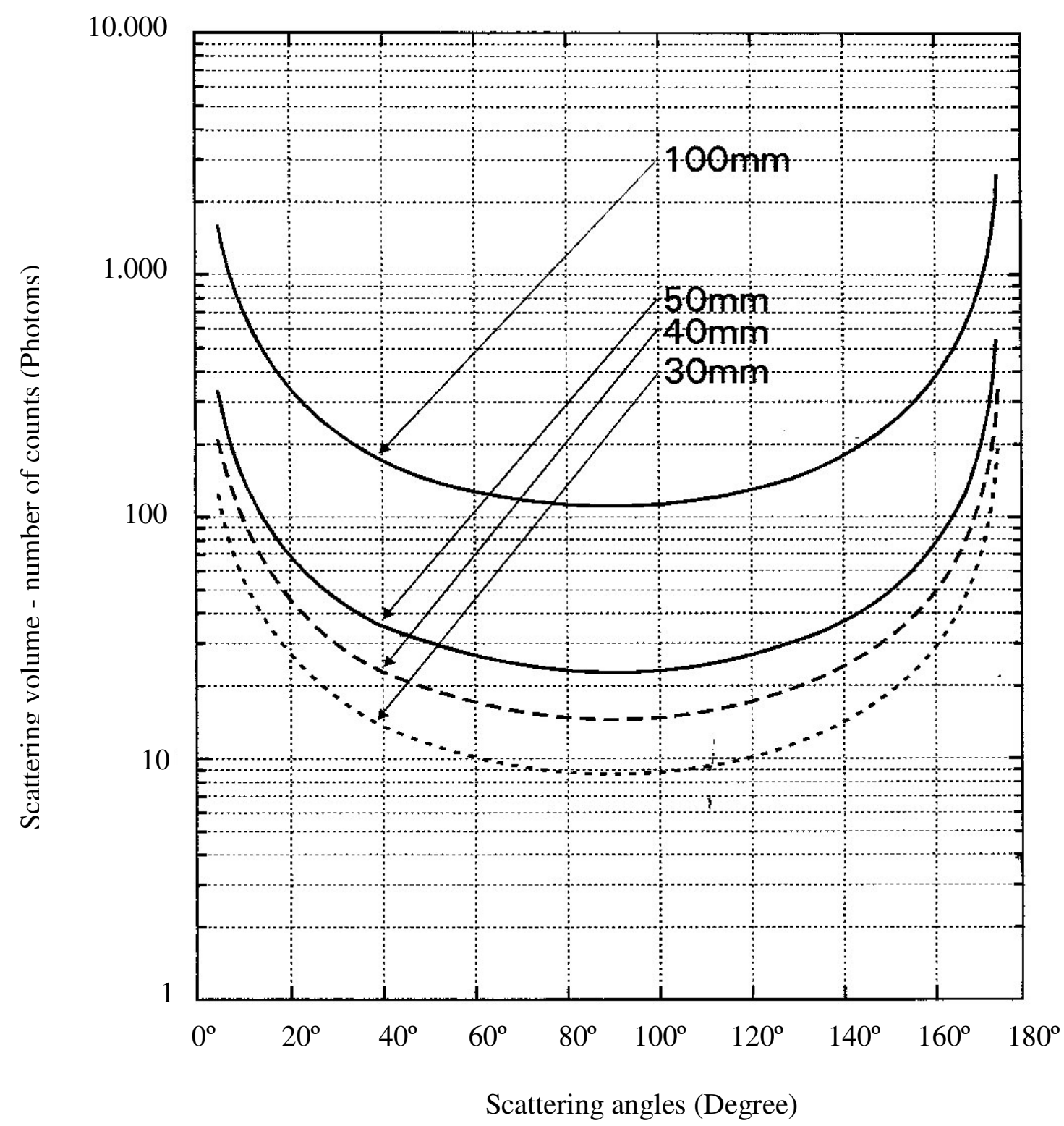

FIGURE 3. Scattering angle dependence versus the scattering volume in terms of the number of counts.

Figure 4 shows both typical Compton spectra without and with soil for energy of $662 \mathrm{keV}$, i.e., in terms of the number of counts per channel versus the pulse height in Volts. Compton Scattering, also known as incoherent scattering, occurs when the incident $\mathrm{X}$-ray photon ejects a electron from an atom and an X-ray photon of lower energy is scattered from the atom. Relativistic energy and momentum are conserved in this process and the scattered X-ray photon has less energy and therefore a longer wavelength than the incident photon. Then, in Figure 4, it is possible to observe the absence of the scatter photopeak in the spectrum obtained without soil, i.e., from an empty container. However, the second spectrum obtained from the soil sample shows the occurrence of a large scatter photopeak 
in a such energy level, which is smaller than the source energy. As expected from equation (2) this result is a function of the enlargement of the Klein-Nishina differential cross-section for the free electrons of the soil sample under analysis.

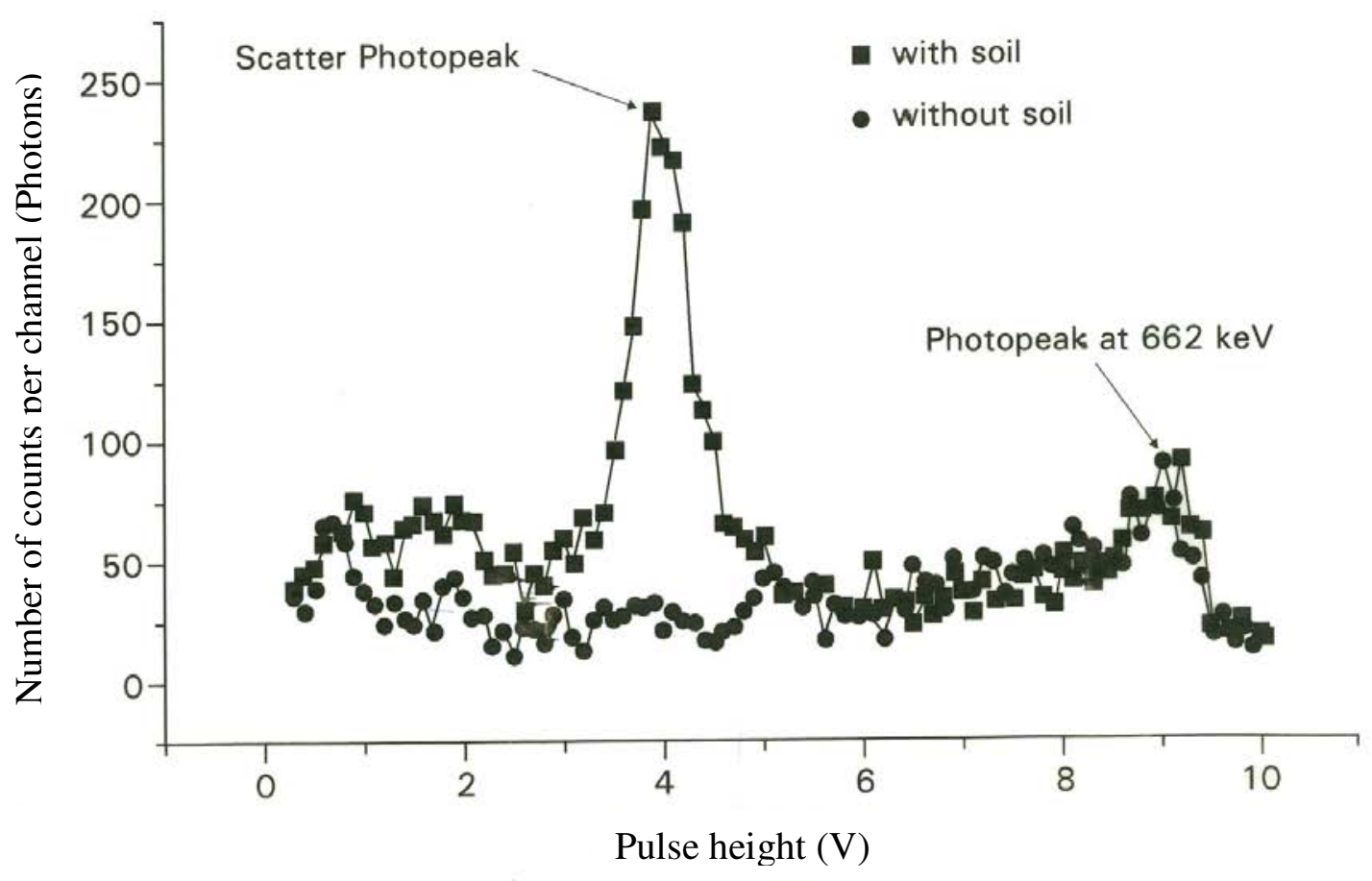

FIGURE 4. Typical spectra obtained for a plexiglass container with and without soil (number of counts of Photons per channel versus pulse height in Volts for energy of $662 \mathrm{keV}$ ).

Figure 5 shows Compton images with $662 \mathrm{keV}$ and $60 \mathrm{keV}$ respectively of a representative Brazilian soil sample, packed into a plexiglass box. The image represent a longitudinal cross section of the sample, made possible by raster motion of data collection of the scanning system. In these images, we have displayed directly volex-by-volex variation of number of scattered photons by pseudo-color levels. A closer study of the images shows some areas with low values for scattered photons to the left of the image. This is due to unequal attenuation in the scattered beam modulated by the distance traversed by the scattered beam within the sample.

Figures 6 and 7 show respectively a comparison of results obtained for both soil density measurements by means of Compton tomography versus transmission tomography method, as well as volumetric water content measurements by means of Compton tomography versus the time domain reflectrometry (TDR) method. Such comparisons have shown coefficients of linear correlation of 0.81 for soil bulk density and 0.79 for volumetric water content measurements.

For a better quantitative Compton scatter tomography, this problem requires additional correction factors. However, these results demonstrate that images obtained using this technique could have applications in soil science comparable to its transmission counterpart, opening the way to a field measuring device based on Compton backscatter photon detection technique. 

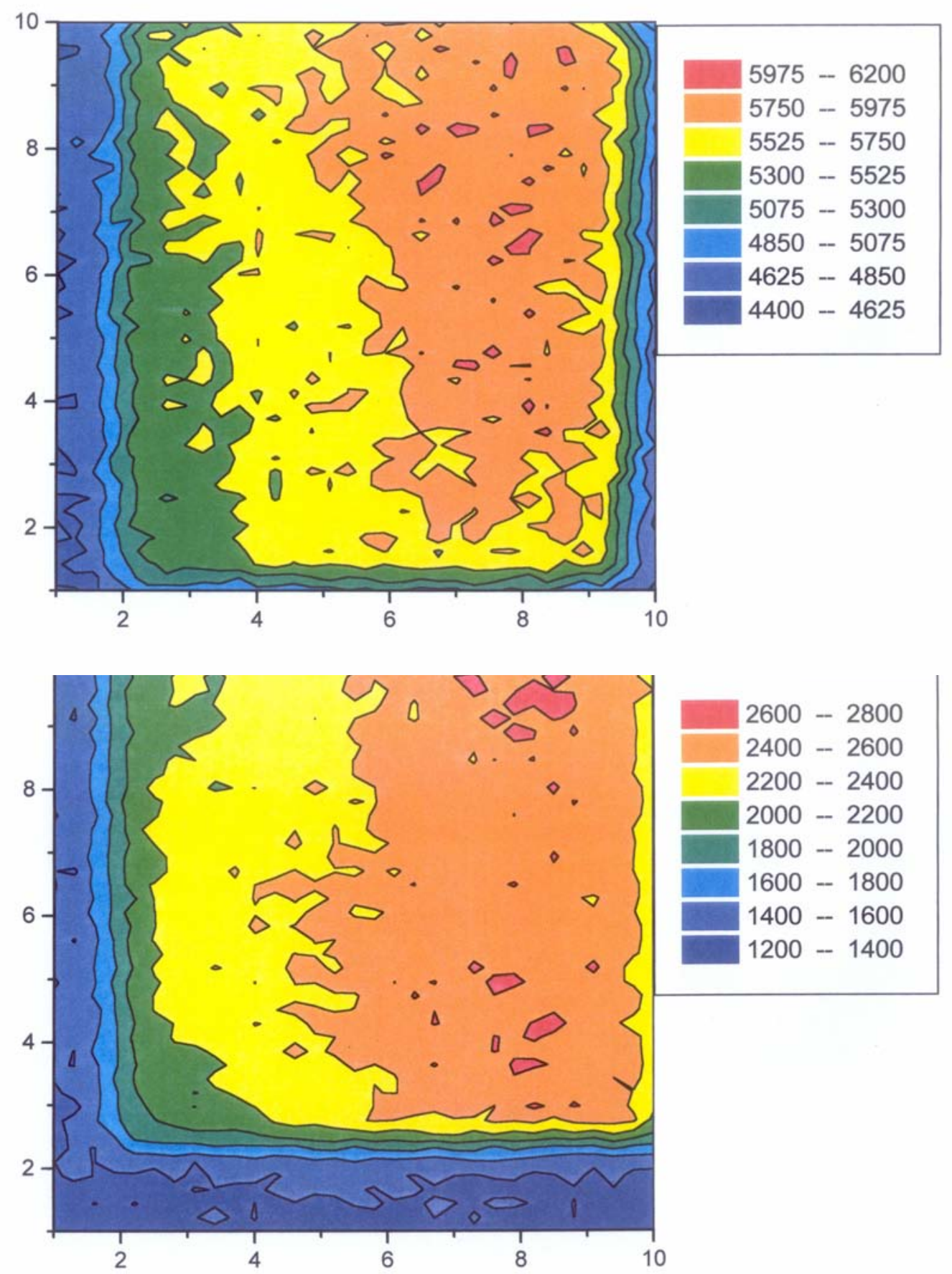

FIGURE 5. (a) $662 \mathrm{keV}$ Compton image of soil sample with different bulk densities packed into a Plexiglass box, i.e., longitudinal cross sections; (b) $60 \mathrm{keV}$ Compton image of soil sample with different water content packed into a Plexiglass box, i.e., longitudinal cross sections. As can be seen, by showing soil density and moisture on a pseudo-color levels scale, values at a pixel position as a map or image can be obtained. 


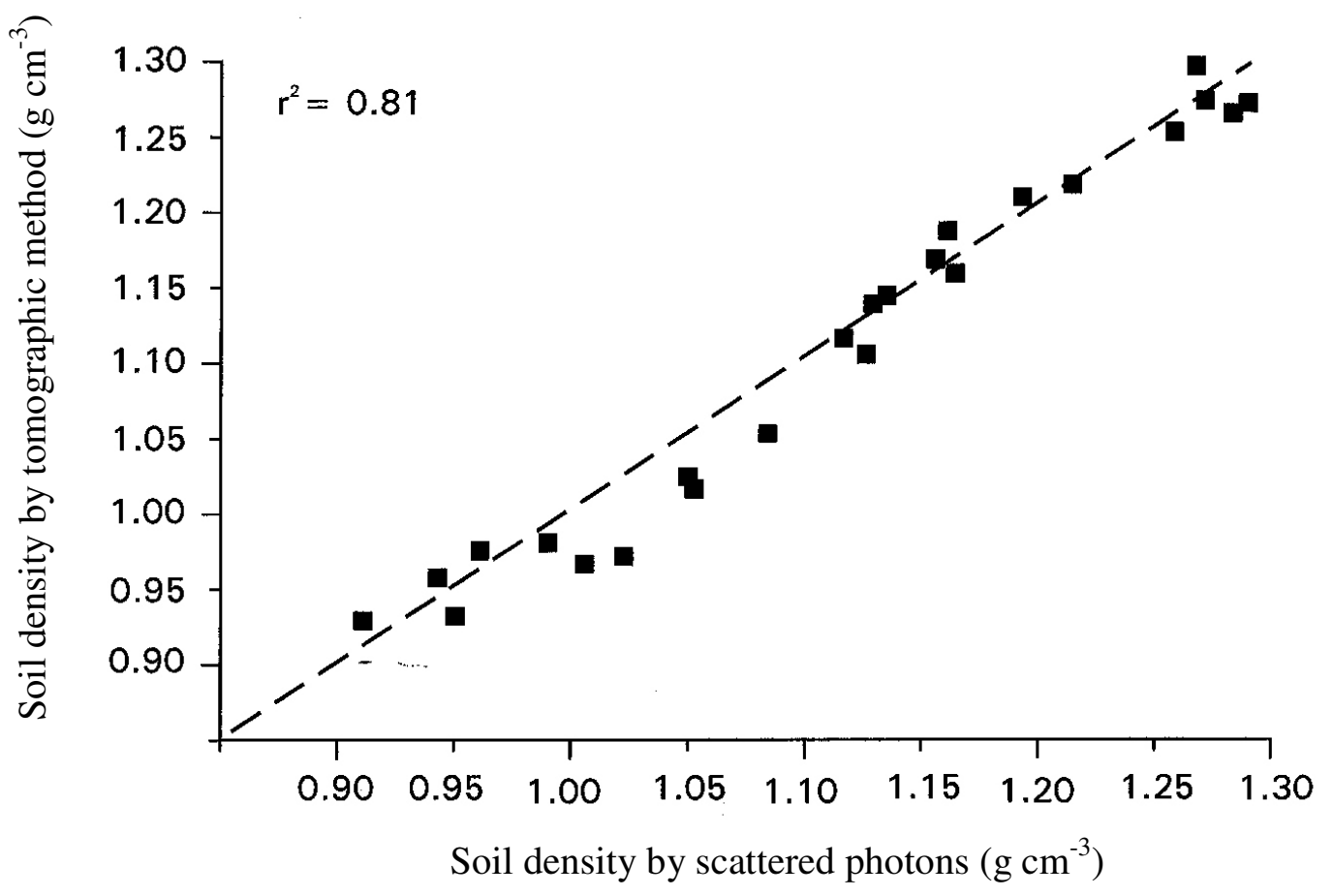

FIGURE 6. Soil bulk density measurements by Compton tomography versus transmission tomography.

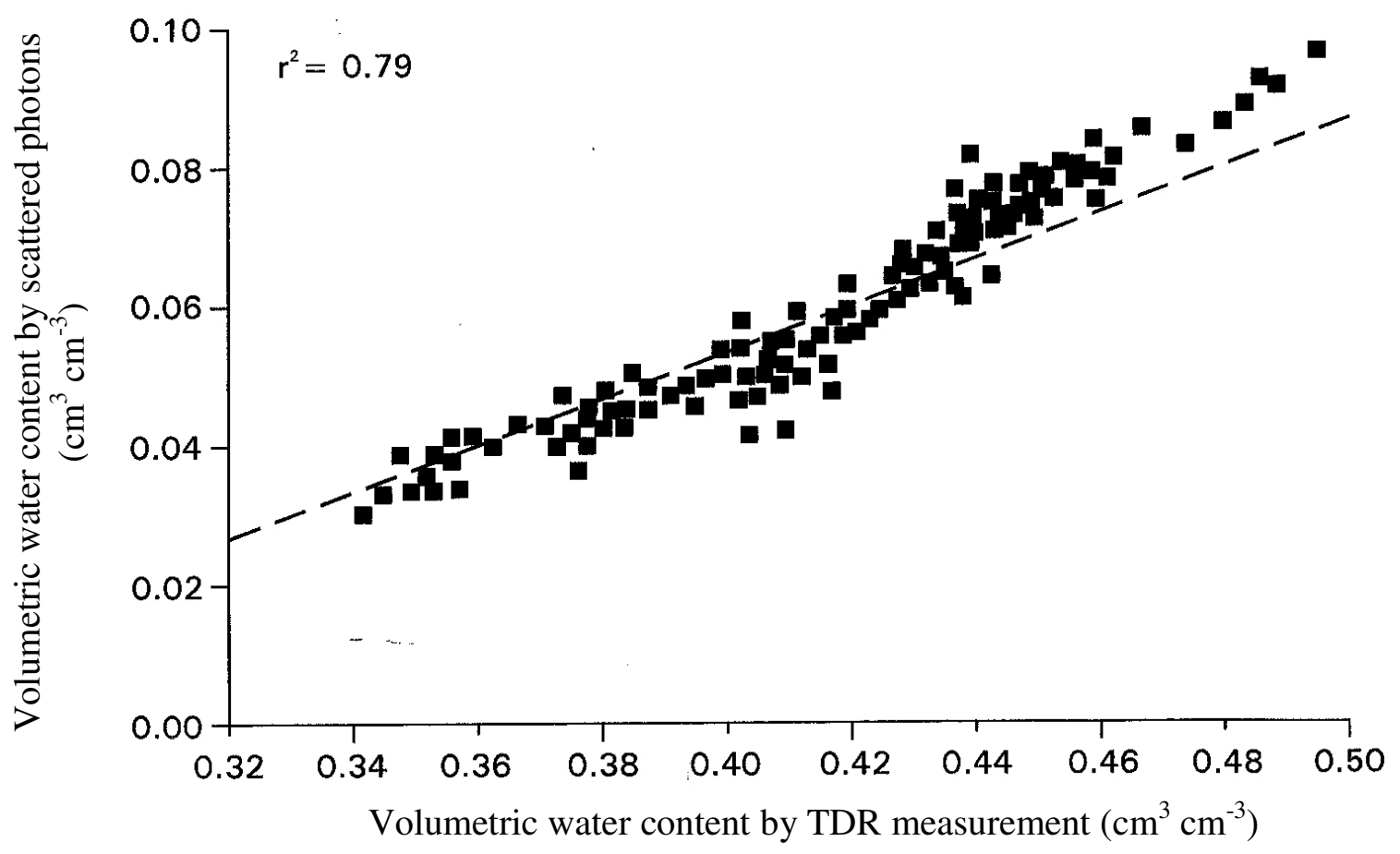

FIGURE 7. Volumetric water content measurements by Compton tomography versus time domain reflectrometry (TDR). 


\section{CONCLUSIONS}

A Compton tomographic scanner dedicated to soil science studies has been designed and constructed at the Embrapa Agricultural Instrumentation Center, São Carlos, Brazil. This equipment, based on both ${ }^{137} \mathrm{Cs}$ and ${ }^{231} \mathrm{Am}$ radioactive sources, has been used to study dependence of the number of scattered photons on soil density and moisture. Quantitative measurements were observed to be distorted by the effect of scattered beam attenuation. Results also show the potentialities for continuing the development of this technique to be employed for in-situ soil study and should therefore be of particular interest to agriculture.

\section{ACKNOWLEDGEMENT}

The authors would like to express their appreciation to Embrapa, Brazilian Research Council $(\mathrm{CNPq})$ and the Third World Academy of Science (TWAS).

\section{REFERENCES}

BALOGUN, F.A.; SPYROU, N.M. Compton scattering tomography in the study of a dense material in a lighter matrix. Nuclear Instruments and Methods B 83, Amsterdam, p.533-8,1993.

BEISER A. Perspectives of modern physics. New York: McGraw-Hill, 1969.

CORMACK A.M. Reconstruction of densities from their projections with applications. Radiological physics, physics, medicine and biology, v.18, n.2, p.195-207, 1973.

CRESTANA S.; MASCARENHAS S.; POZZI-MUCELLI R.S. Static and dynamic three-dimensional studies of water in soil using computed tomographic scanning. Soil Science, Madison,v.140, n.5, p.326-32, 1985.

CRUVINEL P.E.; CESAREO R.; CRESTANA, S.; MASCARENHAS S. X and Gamma rays computerized minitomograph scanner for soil science. IEEE Transaction on Instrumentation and Measurements, New York, v.39, n.5, p.745-50, 1990.

CRUVINEL P.E. X and Gamma ray computerized mini-scanner for multidisciplinary Use. 1987. 329 f. Thesis (Doctoral) - University of Campinas, UNICAMP, Campinas, 1987.

GIGANTE, G.E.; HANSON, A.L. Evaluation of geometrical contribution to the spread of the Compton scatter energy distribution. Physical Review A, New York, v.40, n.1, p.171-80, 1989.

HAINSWORTTH, J.M.; AYLMORE L.A.G. The use of Computer-Assisted Tomography to determine spatial distribution of soil water content. Austrian Journal of Soil Research, Collingwood, v.21, p.43543, 1983.

HOUNSFIELD G.N. Computerized transverse axial scanning (Tomography): Part 1. Description of system. Britannic Journal of Radiology, v.46, p.1016-22, 1973.

PETROVIC A.M.; SIEBERT J.E.; RIEKE P.E. Soil bulk density analysis in three dimensions by Computed Tomographic Scanning, soil water content. Austrian Journal of Soil Research, Collingwood, v.21, p.445-50, 1982. 